\title{
Lifestyle of the Nomadic River Gypsies and their Threat Narrative: A Tale of Two Villages in Bangladesh
}

\author{
Mohammad Sujoun Lasker ${ }^{1 *}$, Liza Mithila Dio ${ }^{2}$, Mohammad Hasan Chowdhury ${ }^{3}$, Md. Sajjat Hossain ${ }^{4}$, Md. \\ Nurul Islam ${ }^{5}$ and Md. Jayed Chowdhury ${ }^{6}$ \\ ${ }^{1}$ Department of Geography and Environment, Jahangirnagar University, Savar, Dhaka (Bangladesh) \\ ${ }^{2}$ Department of Statistics, Tejgaon University College, Dhaka, (Bangladesh) \\ ${ }^{3}$ Department of Food Technology and Nutrition Science, Noakhali Science and Technology University (Bangladesh) \\ ${ }^{4}$ Department of Mass Communication and Journalism, Begum Rokeya University, Rangpur (Bangladesh) \\ ${ }^{5}$ Professor, Dept. of Geography and Environment, Jahangirnagar University, Savar, Dhaka (Bangladesh) \\ ${ }^{6}$ Faculty of Animal Science and Veterinary Medicine, Sher-e-Bangla Agricultural University, Dhaka (Bangladesh)
}

Submission: February 18, 2019; Published: March 14, 2019

*Corresponding author: Mohammad Sujoun Lasker, Department of Geography and Environment, Jahangirnagar University, Savar, Dhaka-1342, Bangladesh

\section{Abstract}

Rivers have been an attention of human activities throughout the history. The livelihood of people is essentially dependent on river and its resources in Bangladesh, but the story of river gypsies is totally different. River gypsies are an ethnic group in Bangladesh. They are known as "water gypsies" or "bedey" to local people. They have their own lifestyles and culture. This paper focuses on the Bangladeshi gypsy community living in Porabari, Savar and Dakatia River in Chandpur Sadar district. This study investigated the gypsies identity in the society and status in the community level and also explore their existing entitlements, need and social rights, and finally examine the problem and threats they frequently face for living an unstable condition in the society. Both primary and secondary data are used in this study. A questionnaire survey and focus group discussion (FGD) are conducted in the study area. Besides these data some secondary data is also used in this study. The major empirical findings are:

a) In Bangladesh context day by day river gypsies lost their culture;

b) One of the major problems in bedey community is water and sanitation, in Chandpur Sadar district 260- 280 families (approximately 500-600 people) use only 4 kacha toilets by sharing. They are directly drinking the river water by using potassium aluminium sulphate (KAl $\left.\left(\mathrm{SO}_{4}\right)_{2}\right)$

c) About their own opinion they use the river water to clean, cook, bath and drink and they have no land;

d) They want their domestic culture, but the problem is they do not want to roam in the river and jungle because their traditional professions losing their demand. Now they want to transform their occupation and many of them runs grocery shop in Porabari;

e) More than 96 percent of bedes are illiterate and they are living below the poverty line, only 3 percent bedey children got the opportunity to be vaccinated against vaccine preventable deadly diseases;

f) In Chandpur Sadar district most of the bedes are enlisted in the voter list but the scenario of Savar Porabari are totally different. Most of the Bedes still could not enlist themselves in the voter list. This research demonstrates the overall lifestyle of gypsy community in the study area. At present they are facing many problems, due to rapid urbanization and drying out the rivers, many of them changing their profession. Government and NGOs should take some initiatives to support them for protect their culture and also need to provide them an environment friendly living place.

Keywords: River Gypsies; Ethnic group; Water and Sanitation; Deadly Diseases; Environment Friendly 


\section{Introduction}

Rivers have been a focus of human activities throughout the history. Rivers have played a leading role in the history of civilization of several country of the world. Bangladesh is a riverine country with hundreds of rivers overlying its landscape. The livelihood of people is essentially dependent on river and its resources in Bangladesh, but the story of river gypsies is totally different. River gypsies are an ethnic group in Bangladesh. They are known as bedey to local people. Bede, a nomadic community and is regarded as "Water Gypsy" or "River Gypsy" or "Nomadic People". Dalton in his brief report mentions Bedayas a gypsy-like tribe [1]. Anthropologist H.K.S. Arefeen [2] mentioned "Bede" as a marginalized Muslim community in Bangladesh perspective [2]. Wise calls the Bedes "bands of vagrants...who correspond to the gypsies of Europe" [3]. The community gives rational explanation of the term "Bede" and defend their Arab origin on the basis of similarity with the Arabic word "Bedouin". Though, Banglapedia mentioned them as descendents of 'Montong' tribe of Myanmar. Bedes are engaged in the snake charming, catching of snakes, curing snake-bites, selling of snakes, traditional and spiritual healing services, magic show and monkey show, selling of bangles and trinkets. According to their own estimate they were 1.5 million in number in 1987 living in Bangladesh [4]. According to a recent estimate Bedays are 500,000 in number in Bangladesh [5]. Around 10,000 nomadic groups roam around Bangladesh and they gather for two months in an area. A survey reported about 65 prominent areas where Bedes come for yearly gathering and some of the Bedes have purchased some land to settle there [6,7].

About 16000 of population have settled by the Bangshi River in Porabari village of Savar Municipality in Dhaka district of Bangladesh which is the biggest gipsy village in the country. Because of their living close by Dhaka city, which is the capital of Bangladesh, the Bede community of Porabari is getting used to a semi-urban lifestyle and is fast losing their traditional lifestyle and culture. On the other hand, in Chandpur 10 no ghat in Dakatia River, there is approximately 500-600 people are living and most of them are Muslim's. Both of them are fighting to protect their culture and tradition.

\section{Aim and Objectives}

The main aim of this study is to explore the state of socio-economic condition of the nomadic river gypsies and also investigate their major problems and threat in the society. To meet the aim of this research several specific objectives are given below:

a) To find out the socio-economic and environmental situation of the river gypsies in the study area;

b) To analyze the major problems of the gypsy community in the study site;

c) To examine the main threat in their culture and also find out their risks and vulnerability.

\section{Study Area}

The study area was selected by two major gipsy villages. One of them is biggest Bede village in the country named Savar Porabari Bede village which is situated in Savar union, vatpara road under the Dhaka district. The location of the Porabari village is $23^{\circ} 51^{\prime} 45.75^{\prime \prime} \mathrm{N}$ latitude and $90^{\circ} 15^{\prime} 20.88^{\prime \prime} \mathrm{E}$ longitude. They live in boat and bank of the Bangshi River. On the other hand, another village situated in the 10 no Ghat in Chandpur Sadar upazila, bank of the Dakatia River. The absolute location of the study area is $23^{\circ} 13^{\prime} 26.13^{\prime \prime} \mathrm{N}$ latitude and $90^{\circ} 38^{\prime} 57.04^{\prime \prime} \mathrm{E}$ longitude which is relatively located beside the Chandpur press club.

\section{Data and Methods}

This is a qualitative research; however, this research has drawn numerous inferences from various secondary sources and quantitative data sets that were available in the public domain. Semi-structured one-on-one interviews and also Focus Group Discussion (FGD) followed by extensive participant observations went into the primary sources of data collection in this research. Interviews of 30 river gypsies were conducted with the help of a semi-structured questionnaire and the guided field-walk method. In-depth interview and group discussion techniques were followed to collect more information on poverty, human deprivation and social exclusion of the Bede community. Secondary data were collected from different published and unpublished materials, journal, newspaper, thesis work, different published and unpublished research and books. Data obtained from the survey were analyzed using descriptive and inferential statistical tools. Different software such as, Microsoft word, Microsoft Excel, SPSS, are used for data analysis.

\section{Results and Discussion}

In this research mainly highlighted in to three major objectives. These are socio-economic and environmental situation of the gypsy villages; their major problems and major threat of their losing domestic culture also their risks and vulnerability. By analyzing respondent's age, monthly income, educational qualification etc. try to understand their socio- economic situation. On the other hand, by analyzing their household structure, toilet structure, sources of drinking water, major diseases, medical facilities, waste management etc. it was examining their health and environmental condition.

\section{Socio-economic and environmental situation}

By analyzing the respondents age, it is found that 20-39 ages are maximum, and they are almost 70 percent. In this age most of them $(10 \%)$ are related to the catching fish. In the age of 35-39 (7\%) of respondents are related to selling of bangles and trinkets (Table 1). Snake catcher are found (7\%) also in the age of 30-34. on the other hand, other respondents are related to snake charming, monkey show, business and snake catching professions. 


\section{International Journal of Environmental Sciences \& Natural Resources}

Table 1: Respondents Age and Occupations

\begin{tabular}{|c|c|c|c|c|c|c|c|c|c|}
\hline \multicolumn{10}{|c|}{ Respondents Age and Occupations } \\
\hline Age Class & $\begin{array}{l}\text { Number of } \\
\text { Respondents }\end{array}$ & $\begin{array}{c}\text { Snake } \\
\text { Charming }\end{array}$ & $\begin{array}{l}\text { Monkey } \\
\text { Show }\end{array}$ & $\begin{array}{c}\text { Snake } \\
\text { Catching }\end{array}$ & Fisherman & Business & Magic Show & $\begin{array}{l}\text { Selling of } \\
\text { bangles } \\
\text { and } \\
\text { trinkets }\end{array}$ & Percentage \\
\hline \multirow{2}{*}{$20-24$} & \multirow{2}{*}{6} & 1 & 0 & 0 & 3 & 1 & 0 & 1 & 20 \\
\hline & & $3 \%$ & & & $10 \%$ & $3 \%$ & & $3 \%$ & \\
\hline \multirow{2}{*}{$25-29$} & \multirow{2}{*}{4} & 0 & 1 & 0 & 1 & 1 & 0 & 1 & 13 \\
\hline & & & $3 \%$ & & $3 \%$ & $3 \%$ & & $3 \%$ & \\
\hline \multirow{2}{*}{$30-34$} & \multirow{2}{*}{5} & 0 & 0 & 2 & 1 & 1 & 1 & 0 & 17 \\
\hline & & & & $7 \%$ & $3 \%$ & $3 \%$ & $3 \%$ & & \\
\hline \multirow{2}{*}{$35-39$} & \multirow{2}{*}{6} & 1 & 0 & 1 & 2 & & 0 & 2 & 20 \\
\hline & & $3 \%$ & & $3 \%$ & $7 \%$ & & & $7 \%$ & \\
\hline \multirow{2}{*}{$40-44$} & \multirow{2}{*}{5} & 1 & 1 & 0 & 1 & 0 & 1 & 1 & 16 \\
\hline & & $3 \%$ & $3 \%$ & & $3 \%$ & & $3 \%$ & $3 \%$ & \\
\hline \multirow{2}{*}{$45+$} & \multirow{2}{*}{4} & 0 & 0 & 0 & 2 & 1 & 0 & 1 & 14 \\
\hline & & & & & $7 \%$ & $3 \%$ & & $3 \%$ & \\
\hline Total & 30 & 3 & 2 & 3 & 10 & 4 & 2 & 6 & $100 \%$ \\
\hline
\end{tabular}

Source: Questionnaire survey, 2018

In the Table 2 it was observed that monthly income of the respondents is not enough. 15000-19000 taka is monthly income of 24 percent respondents. 20 percent of people earned 50009000 taka monthly and 20000-24000, 10000-14000 taka earned by 16 percent respondents. 10 percent respondent's income level is 25000-29000 taka. In Bangladesh per capita income is 4,040 PPP dollars [8].

Table 2: Respondents Monthly Income.

\begin{tabular}{|c|c|c|}
\hline \multicolumn{3}{|c|}{ Respondents Monthly Income } \\
\hline $\begin{array}{c}\text { Respondents } \\
\text { Monthly Income }\end{array}$ & $\begin{array}{c}\text { Number of } \\
\text { Respondents }\end{array}$ & Percentage \\
\hline $5000-9000$ & 6 & 20 \\
\hline $10000-14000$ & 5 & 16 \\
\hline $15000-19000$ & 7 & 24 \\
\hline $20000-24000$ & 5 & 16 \\
\hline $25000-29000$ & 3 & 10 \\
\hline $30000-34000$ & 2 & 7 \\
\hline $35000-39000$ & 2 & 7 \\
\hline Total & 30 & $100 \%$ \\
\hline
\end{tabular}

Source: Questionnaire survey, 2018.

It was observed that (Figure 1) about 97 percent gypsies are illiterate. Only 2 percent gypsy was completed primary education. 1 percent is found who can complete class 8 or 9. A large majority of children cannot attend schools because they stay all the months of a year with their parent outside home, and travel from one place to another. Because of illiteracy Gypsies cannot enjoy the independence to select any other occupation except the hereditary and traditional ones. It was also observed that (Figure $2 \& 3$ ) almost 50 percent of the respondents living in a boat. 34 percent live in kacha house, 6 percent in tin shed, 3 percent people live in half pacca house which is found in Savar Porabari, and 8 percent are live in the bank of river.

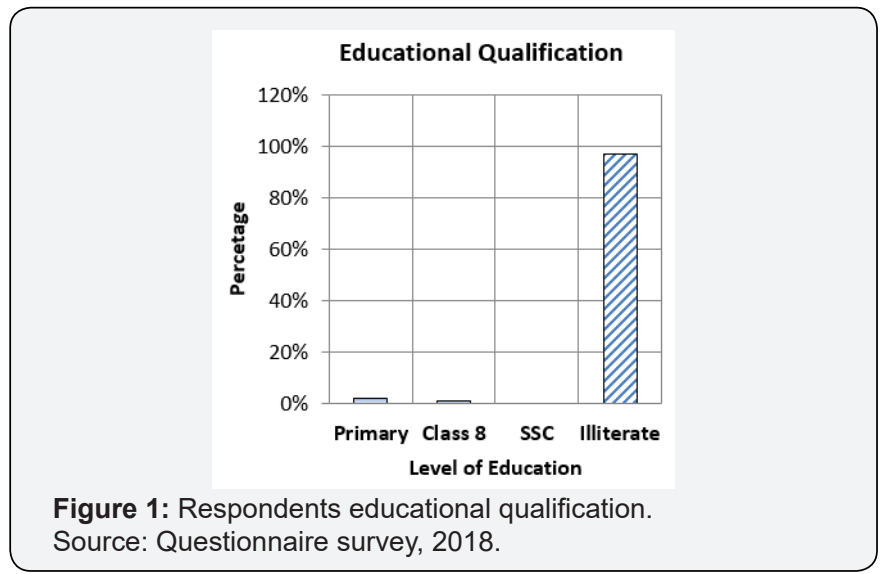

Figure 1: Respondents educational qualification Source: Questionnaire survey, 2018.

Respondent Household Structure

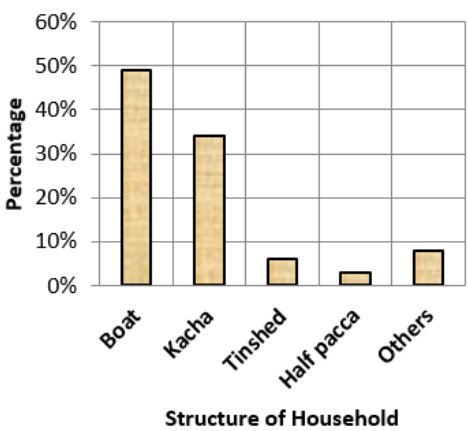

Figure 2: Respondents household structure. Source: Questionnaire survey, 2018. 


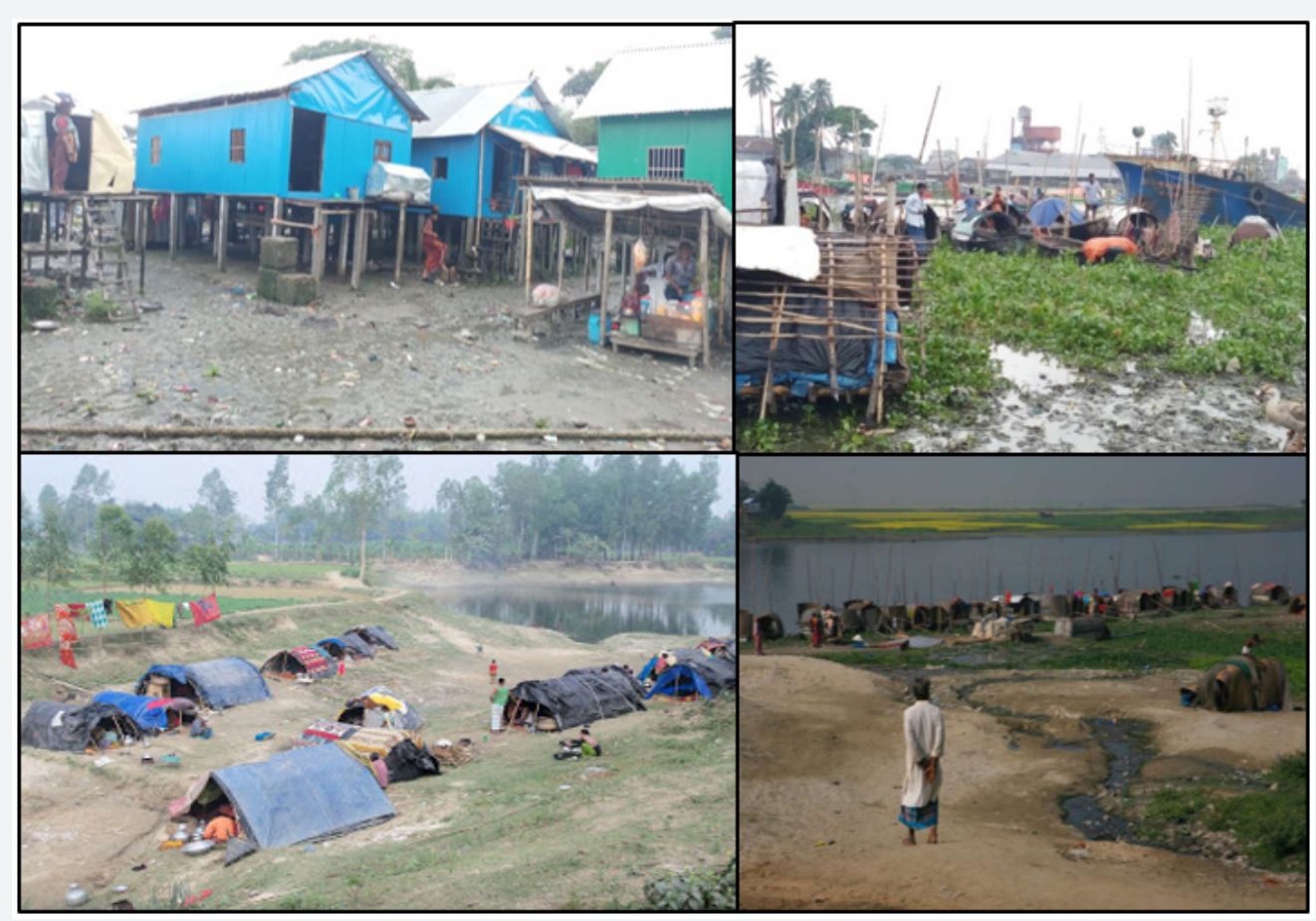

Figure 3: Household structure of the Gypsies, accordingly chadpur and Porabari (Source: Author, 2018).

\section{Health status and environmental situation}

Pure drinking water is very important for maintaining sound health. In the analysis it was observed that 95 percent of the gypsies drink the river water (Figure 4). In that case they are directly drinking the river water by using potassium aluminium sulphate (KAl (SO4)2). Four percent of the villagers used to drink tube well water because they live in the land permanently in Porabari Savar. Others are using different source of water by the purpose of their business and travelling. Most of the villagers (96\%) directly through their waste in to the river (Figure 5). Because of their illiteracy and unconsciousness of the environment protection they through all of the waste in to the river. About 2 percent are through their waste in the dustbin because they live in the land and try to take the surroundings neat and clean.

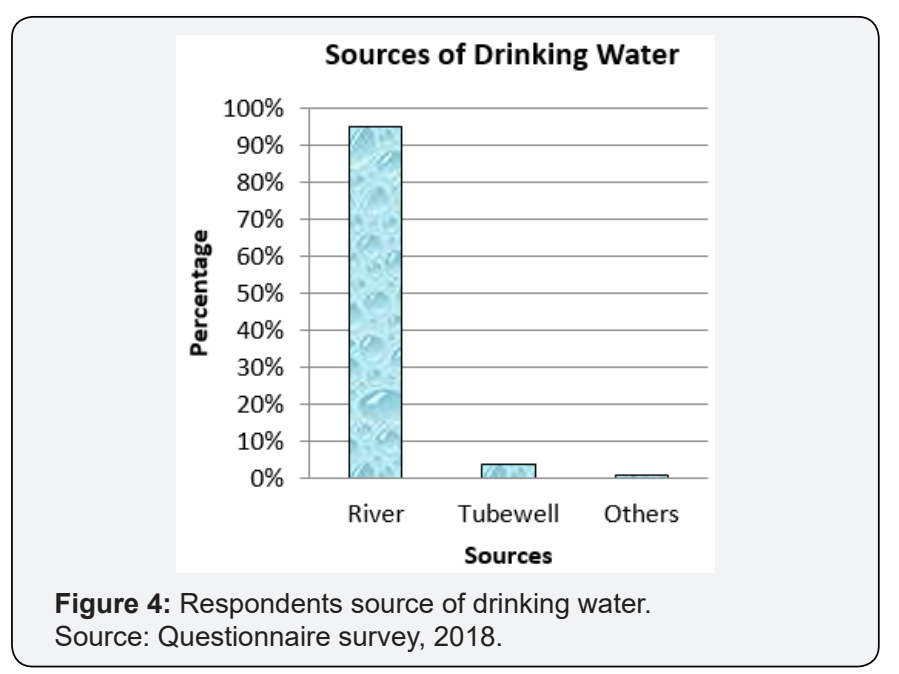

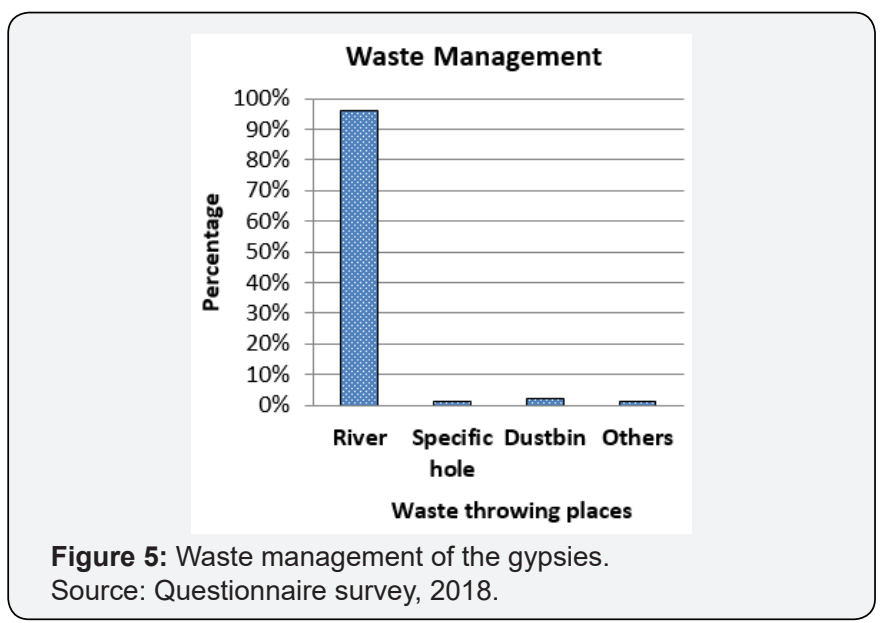

It was observed that (Table 3) 60 percent of the respondents used kacha toilet, 17 percent used ring slub and 13 percent are using hanging toilets. In Bangladesh there are 57.5 percent people are used well toilets [9].

Table 3: Respondents Structure of toilets.

\begin{tabular}{|c|c|c|}
\hline \multicolumn{3}{|c|}{ Respondents Structure of Toilets } \\
\hline Structure of Toilet & Number of Respondents & Percentage \\
\hline Ring Slub & 5 & $17 \%$ \\
\hline Kacha & 18 & $60 \%$ \\
\hline Hanging & 4 & $13 \%$ \\
\hline Others & 3 & $10 \%$ \\
\hline Total & 30 & $100 \%$ \\
\hline
\end{tabular}

Source: Questionnaire survey, 2018. 
In this research it was observed that about 47 percent of people are assailing from diarrhea, 13 percent dysentery and 12 percent are attacked by pneumonia (Figure 6). Fever are their common diseases, they also attacked by the typhoid, malaria and skin diseases.

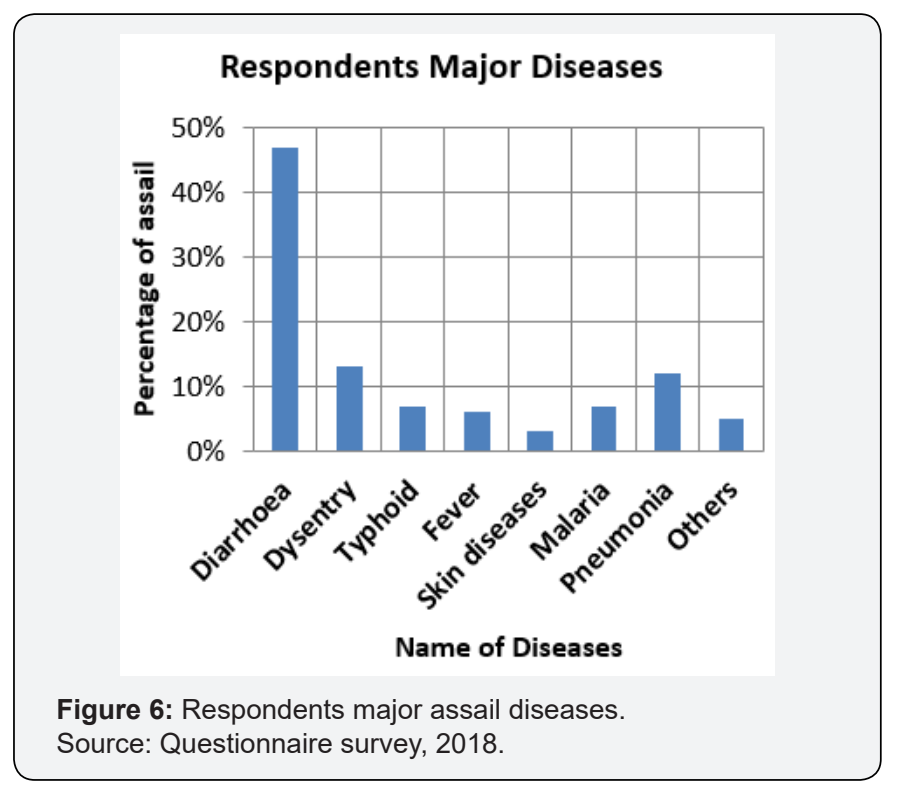

Most of the people (56\%) are going to the government hospital for received treatment (Figure 7). some of them are going to local medical care center (25\%). On the other hand, some people also visit their quack doctor and others are taking different treatment.

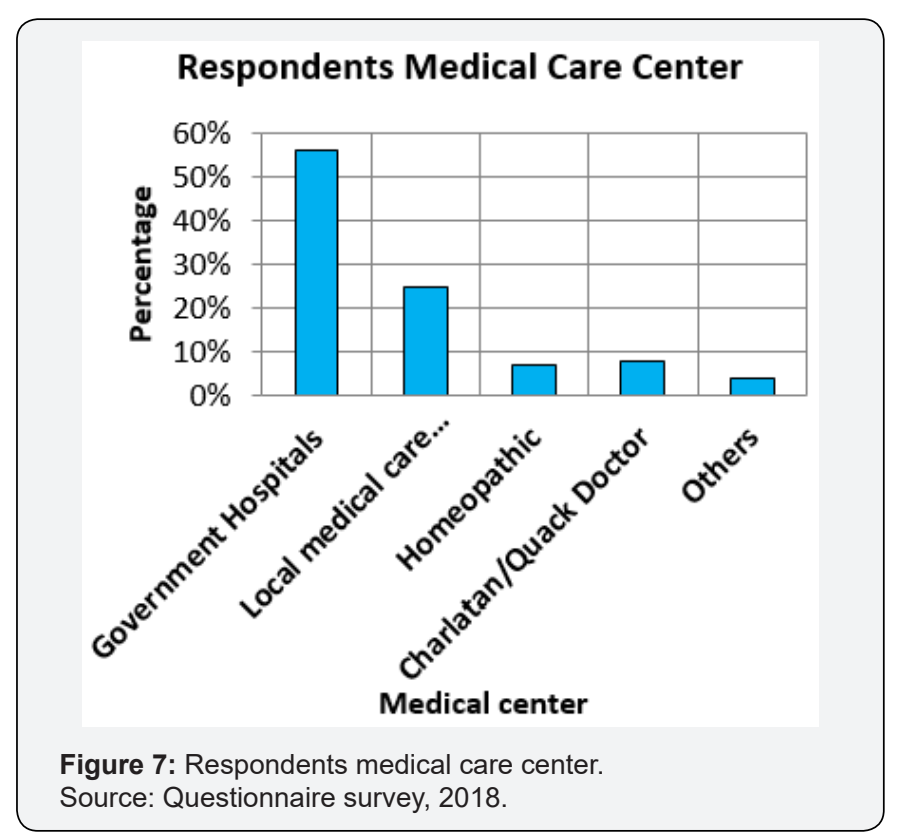

\section{Loss of biodiversity}

The gypsies are also snake charmer. They point out that every day more than 200 women of their community spread out in different areas of the capital and adjoining villages to earn their livelihood by demonstrating their skills as snake charmers. A large number of Bedes live on snake related trading e.g. snake catching and snake selling (Table 4).
Table 4: Market Price of different snakes.

\begin{tabular}{|c|c|}
\hline \multicolumn{2}{|c|}{ Price of Different Snakes } \\
\hline Name of Snake & Price (Taka) \\
\hline Cobra & $800-1500$ \\
\hline Python & $1000-7000$ \\
\hline Lau doga & $400-600$ \\
\hline Keute & $400-700$ \\
\hline KalNagini & $400-1200$ \\
\hline Kata Dubal & $500-1000$ \\
\hline Shankhini & $450-1200$ \\
\hline
\end{tabular}

(Source: FGD, 2018).

The presence of snakes reduces crop damage by the rats in the crop fields. Snake catching by the Bedes without creating any scope for snake reproduction causes loss of different species of snakes and is creating an imbalance in the ecosystem. Snake catchers are facing difficulties in collecting snakes from the forests of Bangladesh because of deforestation and excessive catching of snakes from forests. Eventually their earnings from snake trading reduced [5]. They polluted the river water which is another cause of water pollution and they also polluted their surroundings that's why people are do not allow the Bedes to anchor in their land because they know that after anchoring the Bedes will pollute the surrounding

environment through defecating in the open places both on land and in water.

\section{Major problems of the gipsy villages}

The Bede community is strictly under privileged from all types of basic requirements of life e.g. food, shelter, education, medical care, etc. They travel almost throughout the whole year by boats on the numerous waterways of Bangladesh and earn their livelihood by selling sundry items, performing jugglery acts, catching snakes, and treating village people by the various riversides with their traditional medicinal formulations [10]. Lack of awareness and health education increases the risk of getting diseases especially communicable diseases in Bede community. An estimate shows that death rate from communicable diseases among the age group 5-14 of the poorest 20 percent of the global population is 67 times higher than that of the richest 20 percent of the global population [11]. The condition of Bede community indicates that the health seeking process and causes of death in this community must be more frustrating than any other socially excluded and deprived ethnic groups in Bangladesh. Though many researchers worked on the culture of the Bede community but until 1999 no research was done on the development crisis of this community [5]. NGOs have launched numerous programs for the poor and marginalized people but almost no development program was launched for the socially excluded and stigmatized Bede Community. Many research works were done on the Bede community, but no research work could find a way for changing or initiate a change process in this community. There are some major 
problems found in the 10 no Ghat Dakatia river gypsies and also the Savar Porabari river gipsies. These are:

a) There is no pure drinking water source in the villages.

b) No electricity and gas in the villages although some peoples living in the land.

c) Without river water, everything's of daily life they bought in the market.

d) There are no permanent educational institutions of their children.

e) Early marriage is a major problem of their community

f) Many children are died by drop in to the water

g) They do not find enough fish in to the river.

h) Pregnant women are attacked in different diseases.

i) Sometimes their boats are sinking in to the water because of natural hazard and also the high tide.

j) 500-600 peoples used averagely only 3 toilets that is a massive problem. k) There are no medical facilities of them, and no one can provide any medicines.

l) Bede has no alphabet, but they practice or restore their language, tradition, custom, song, dance and culture orally.

m) They do not have any control over land and local or national political power.

n) Almost all the Bedes are not included in the voter list of Bangladesh.

o) They want domestic culture, but they do not want to roam in jungles and catch snakes.

p) Lack of nutrition and food security.

q) Lack of opportunity for savings.

r) Gypsies do not have land, so they can not apply for Bank loan or NGO microcredit.

s) Diminishing Market Demand for Services and products provided by Bedes.

t) Illegal Seasonal Migration and Violation of Human rights (Figure 8).

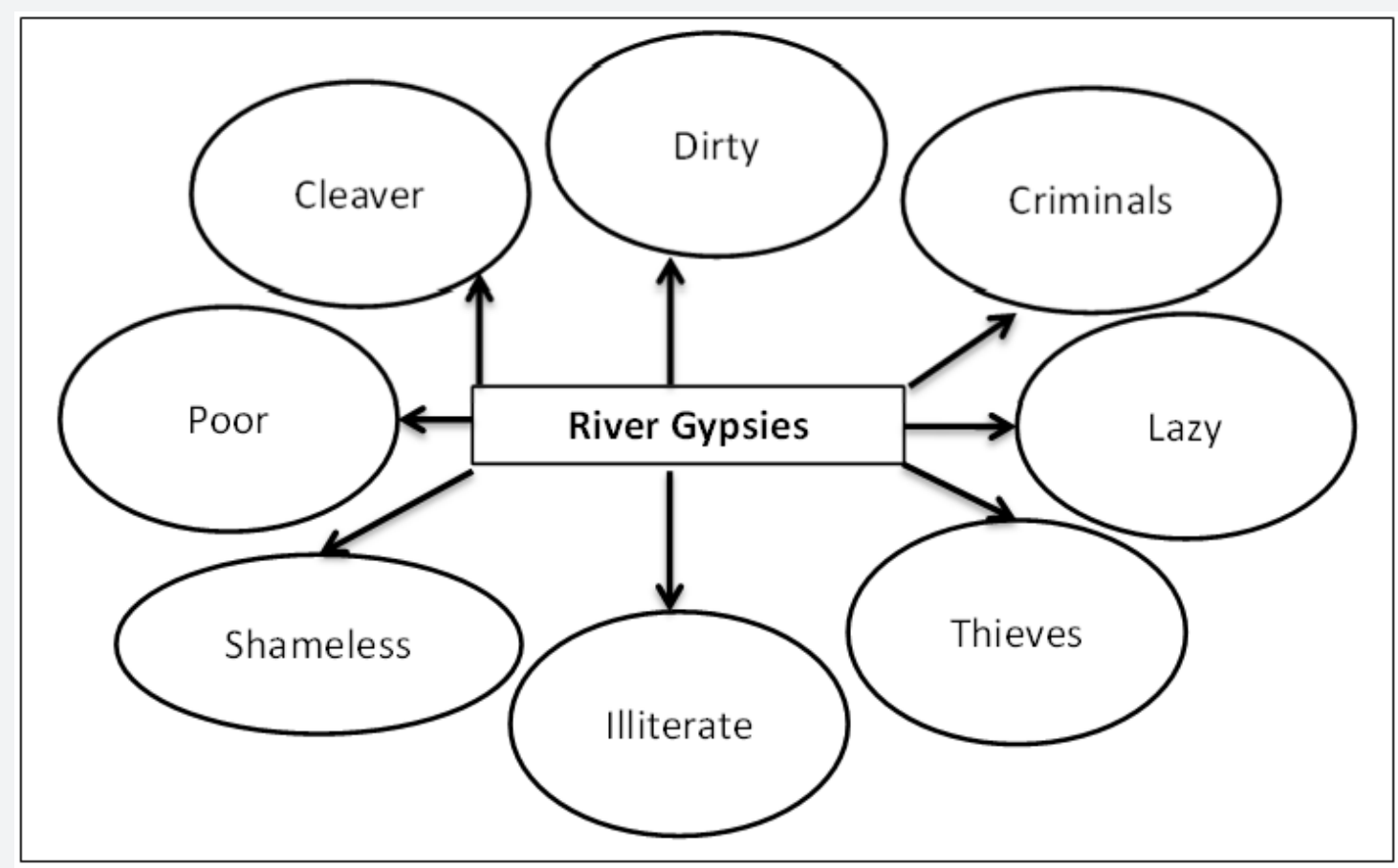

Figure 8: General people's perception about the gypsies (Source: Author, 2018).

\section{Major threat in their culture}

Rivers are life for Gypsies. For hundreds of years, they have meandered along involved waterways, charming snakes, training monkeys, selling trinkets, performing magic and healing people. Most of the Gypsies are live in below the poverty line, they are illiterate, and children are married at age 11 on average. Some of them told that, it is a myth for them that they want their domestic culture. They said that they do not want to roam the jungles and catch snakes. They and their children want to be educated so that they can go abroad. "Our traditional occupations are losing their demand. People no more trust in our mystical healing service. Snake charming has also lost its acceptance," said Khadiza Akter, 
who once lived a conservative gypsy life but now runs a grocery shop Savar Porabari. Halima Begum also added "Earlier, we used to earn well when there were no doctors in the village. But people don't trust in herbal medications or magic anymore. We earned around 500-1,000 taka a day - now maybe 50, 100" But most Bedes are love their centuries-old expertise and healing confidences. They do not want to wildness their old-style lifestyle because they trust they were born to be river wanderers (Figure 9).

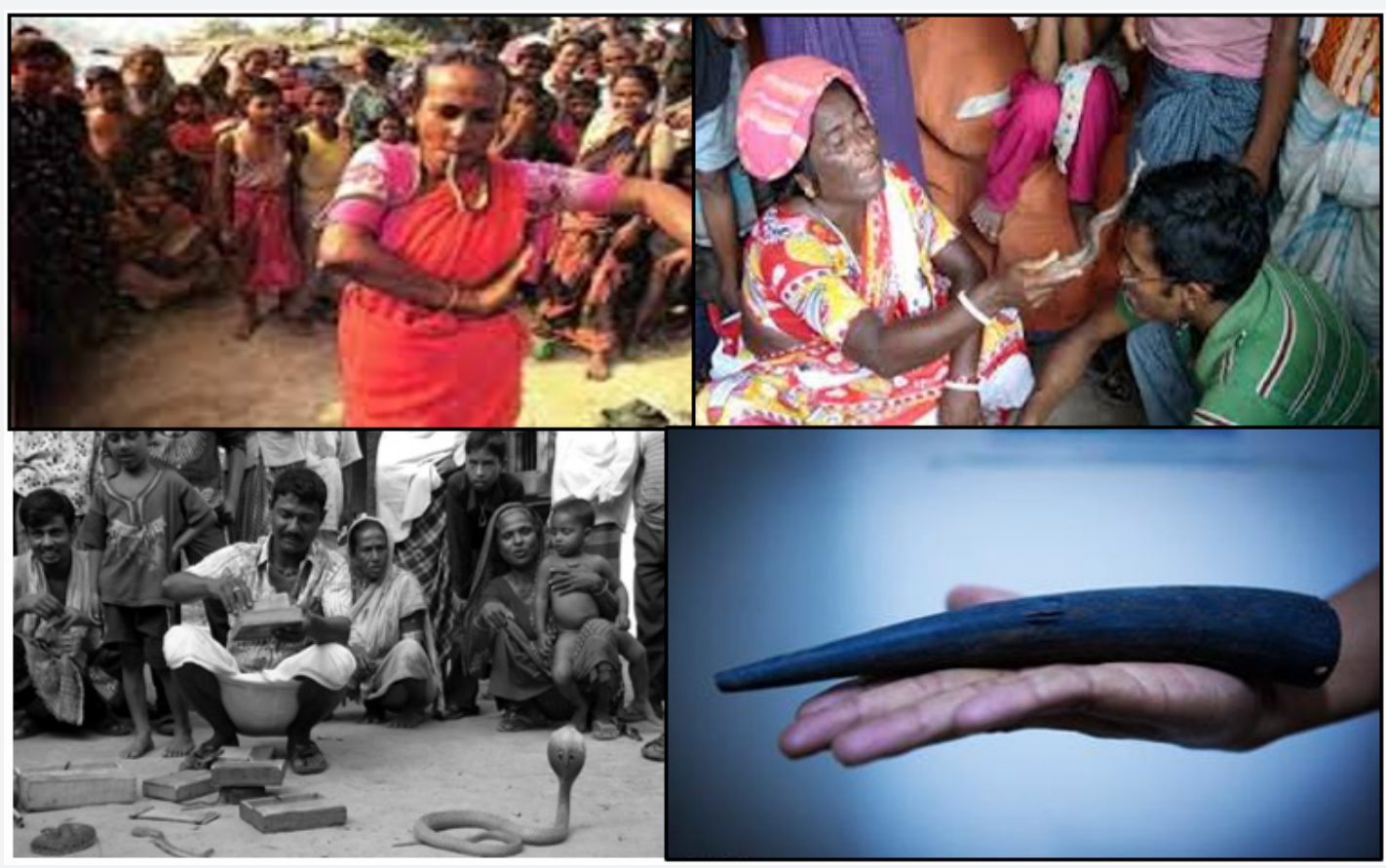

Figure 9: Some of Traditional Bede Culture.

\section{Risks and vulnerability}

Gypsies are often become endangered during the uneven weather. Due to storms, heavy rains and wind their boats sometimes get sunk in the river. Although they live on slight and insecure boats, they are at danger of sinking of their children into water. Most of the pieces of land on those Bedes settled are on the bank of the river. So, river erosion destroys a good number of Bede households every year. Day by day they are losing their heritage. They believe that it is not possible for them to survive by retaining the gypsy culture, because they understand the world has changed so much. This is a major problem for losing their traditional culture.

\section{Recommendations}

a) Government organizations and also different Non-Government Organizations and their development partner organizations should acknowledge the special need of education for the gypsy children who are roaming different Gypsy groups.

b) Government should include them in primary education.

c) Government Primary Education department can plan for a flexible primary education system for this community because they are always move from one place to another place; they stay in one place just for 2 or 3 months. d) Low cost education program should be promoted for them and the best option is to launch a 2-3 month's teachers' training program for the Bede teachers.

e) Mobile school program should be promoted for their children to progress the quality of education.

f) Environmental education should be promoted in Bede community with importance because their live and livelihood is very closely influenced by their surrounding environment.

g) Gypsies use the same river water for drinking, cooking and using in other domestic purposes where they evacuate. The condition of environmental, sanitation and hygienic practices in gypsy community is highly injurious to their own health and disastrous to adjacent environment. Safe water, sanitation and environmental health should be executed in this community.

h) Gypsy women need leadership and entrepreneurship development training, because they are good entrepreneur.

i) It is high time to promote them stop the child marriage and also promote female education.

j) Gypsies are denied including in the voter list since they do not have any land tax certificate or SSC certificate. All the gypsies should be enlisted as voters in Bangladesh. 


\section{Conclusion}

River gypsies are an ethnic group in Bangladesh. They are known as bedey and water gypsies to local people. They live in groups and they have own lifestyle and culture. They have no land and they lead a nomadic life by travelling from one place to another. In the study areas, Chandpur Dakatia River gypsies and Savar Porabari gypsies occupations are different. Surveys were conducted among a large Bede community, who reside in boats on the Bangshi River by Porabari village of Savar area in Dhaka district and 10 no. Ghat, Chandpur Sadar upazila in Dakatia river of Bangladesh. In Chandpur most of the gypsies are fisherman and some of them doing different business. On the other hand, in Savar Porabari, some are snake charmer, business man, snake catcher, fisherman etc. They roam across the rivers and waters in small country boats. These boats are their houses. Throughout the monsoon, they remain busy with fishing. They also dive for natural pearls in waters. Men and women both are catch snakes and entertain people with snake charming and sell herbal cures. Women go from door to door sell bangles, cosmetics and many other things. They also try to heal pains of old people often by sucking out blood from their body. They have no education. So, the authority feels the need to bring them under formal education network. Some voluntary organizations are running special schools on boats to educate river gypsy children in some areas.

\section{Conflict of Interests}

The authors declare that they have no competing interests.

\section{Sources of Financial Support}

There is no funding to be disclosed.

\section{Author's Contribution}

Mohammad Sujoun Lasker contributed to the conception, design, implementation of the research, analysis of the results and took the lead in writing the manuscript. Liza Mithila Dio,
Mohammad Hasan Chowdhury, Md. Sajjat Hossain and Md. Jayed Chowdhury contributed to the acquisition of data, participated in the design of the research \& in writing of the manuscript. Md. Nurul Islam; Professor, Jahangirnagar University conceived of the research, participated in its design, coordination and helped to write of the manuscript. All authors read and approved the final manuscript.

\section{References}

1. Dalton ET (1978) Tribal History of Eastern India. Cosmo Publications, New Delhi, India.

2. Arefeen HKS (1992) Sub-culture: Society of Bangladesh, Samaj Nirikhan, Vol 46. Samaj Nirikhan Kendra, Dhaka, Bangladesh.

3. James W (1883) Notes on the Races, Castes and Traders of Eastern Bengal. Volume 2, Harrison \& Son, London, UK.

4. Habibur R (1990) The Shandar-Beday Community of Bangladesh: A Study of a Quasi-Nomadic People. Unpublished Ph.D. Thesis. University of Dhaka. Dhaka: Bangladesh.

5. Maksud AKM (2006) Participatory Action Research for Human Development of Nomadic Bede Community, GrambanglaUnnayan Committee and Research Initiatives, Bangladesh (RIB), Dhaka.

6. Maksud AKM (2002) Prospects and Possible Interventions and Potentials for Sustainable Development in Beday Community, Grameen Trust, Dhaka.

7. Maksud, AKM (2002) The Nomadic Bede Community and their Mobile School Program. Grambangla Unnayan Committee Dhaka, Bangladesh.

8. World Bank (2017) Bangladesh/GNI per capita income.

9. DPHE (2010) Sanitation scenario, Bangladesh.

10. Seraj S, Rahmatullah M, Khudha MME, Aporna SA, Khan MSH, et al. (2012) Tribal Formulations for Treatment of Pain: A Study of the Bede Community Traditional Medicinal Practitioners of Porabari Village in Dhaka District, Bangladesh. Afr J Tradit Complement Altern Med 10(1): 26-34.

11.Gwatkin DR (2001) Poverty and Inequalities in Health within developing countries: filling the information gaps, Poverty, Inequality and Health. Oxford University Press, London, UK.

This work is licensed under Creative Commons Attribution 4.0 License DOI: 10.19080/IJESNR.2019.17.555973

\section{Your next submission with Juniper Publishers} will reach you the below assets

- Quality Editorial service

- Swift Peer Review

- Reprints availability

- E-prints Service

- Manuscript Podcast for convenient understanding

- Global attainment for your research

- Manuscript accessibility in different formats

( Pdf, E-pub, Full Text, Audio)

- Unceasing customer service

Track the below URL for one-step submission https://juniperpublishers.com/online-submission.php 